\title{
Acute pneumonitis secondary to subcutaneous silicone injection
}

This article was published in the following Dove Press journal:

International Journal of General Medicine

16 June 2011

Number of times this article has been viewed

Priya Gopie

Sateesh Sakhamuri

Anu Sharma

Sanjeev Solomon

Surujpal Teelucksingh

Clinical Medical Sciences, University of the West Indies, St Augustine, Trinidad

Correspondence: Priya Gopie

Department of Clinical Medical Sciences, Eric Williams Medical Sciences Complex, Champ Fleurs, Trinidad and Tobago

$\mathrm{Tel}+$ I 8687831879

Fax + I 868662954 I

Email priyagopie@hotmail.com
Abstract: Following silicone injection, end organ toxicity can occur. To our knowledge this report documents the first case of silicone embolization in the Caribbean and serves to highlight an emergent danger associated with its illicit use for cosmetic purposes in this region.

Keywords: silicone, silicone embolism, silicone pneumonitis, alveolar hemorrhage, pneumonitis

\section{Case}

A 38-year-old female presented to the emergency department with sudden onset of shortness of breath, chest pain, and hemoptysis. On examination, the patient was afebrile and positive findings included tachycardia (pulse rate of 130 beats per minute), tachypnea (respiratory rate of 35 breaths per minute), and $\mathrm{SpO}_{2}$ by pulse oximetry was $86 \%$ on room air. The trachea was central and there was symmetrical chest expansion, with resonance on percussion and clear breath sounds bilaterally. Arterial blood gas results revealed hypoxemia and a respiratory alkalosis ( $\mathrm{pH}$ : 7.46; $\mathrm{pCO}_{2}: 30 \mathrm{mmHg} ; \mathrm{pO}_{2}: 55 \mathrm{mmHg} ; \mathrm{HCO}_{3}: 22 \mathrm{mmol} / \mathrm{L} ; \mathrm{SaO}_{2}: 88 \%$ ). Initial chest X-ray was normal and CT pulmonary angiography (CTPA) showed no evidence of pulmonary embolism, but there was basal and peripheral interstitial shadowing bilaterally (Figure 1). The clinical impression at that time was acute interstitial pneumonia with possible pulmonary embolism (PE). High flow $\mathrm{O}_{2}$ was administered together with intravenous levofloxacin $750 \mathrm{mg}$ orally and intravenous hydrocortisone $200 \mathrm{mg}$ every 6 hours. Since the patient's coagulation profile was normal and there were no obvious vascular deformities noted in CT scan, subcutaneous enoxaparin $60 \mathrm{mg}$ twice daily was also started. By day 3, her condition had worsened with increasing hemoptysis and decreasing $\mathrm{SpO}_{2}$ ranging from $83 \%$ to $85 \%$. Repeat arterial blood gas was consistent with worsening hypoxemia and partially compensated respiratory alkalosis (pH: 7.48; $\mathrm{pCO}_{2}: 26$ mmHg; $\mathrm{pO}_{2}: 50 \mathrm{mmHg} ; \mathrm{HCO}_{3}: 18 \mathrm{mmol} / \mathrm{L} ; \mathrm{SaO}_{2}: 80 \%$ ). Chest examination now revealed crepitations bilaterally in both bases, and chest X-ray showed bilateral basal nonhomogeneous opacities with obliteration of costophrenic angles (Figure 2). The patient was repeatedly counseled about the seriousness of her condition and further inquiry revealed that the patient had received silicone injection on her buttocks, 6 hours prior to her presentation. Approximately $500 \mathrm{~mL}$ of silicone was administered by an unlicensed aesthetician. Over the next few days, the patient's 


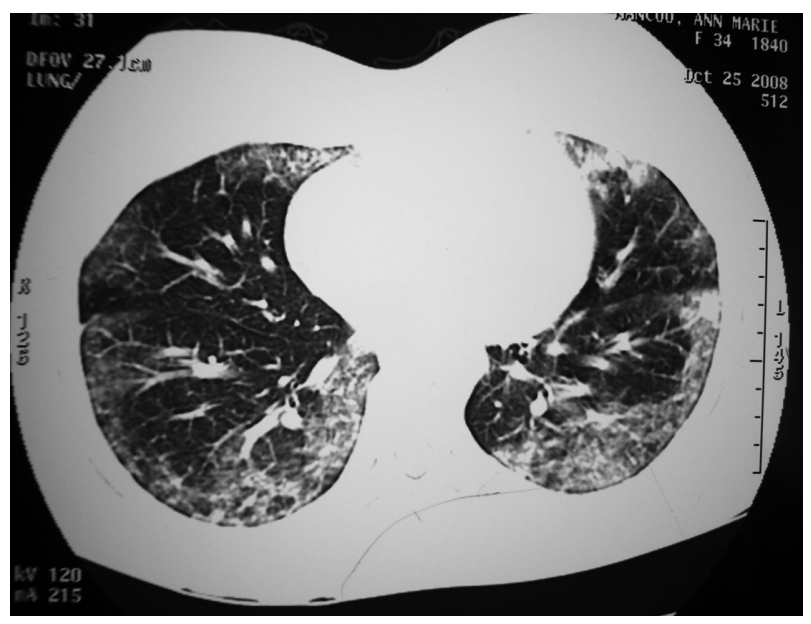

Figure I CT pulmonary angiography showing basal and peripheral interstitial shadowing bilaterally.

oxygenation improved but she had persistent hemoptysis, resulting in a drop in hemoglobin from $11 \mathrm{~g} / \mathrm{dL}$ to $9 \mathrm{~g} / \mathrm{dL}$ requiring transfusion with two units of packed red blood cells. It was also noted that there was whitish material admixed on the sputum. (Figure 3) This was sent for sputum cytology which revealed inflammatory cells containing neutrophils and lymphocytes. Of note, her repeat chemistry at this time showed an elevated aspartate aminotransferase (AST) of 110. By day 7, the patient was showing clinical signs of improvement with $\mathrm{SpO}_{2}$ ranging from $93 \%$ to $95 \%$. By day 13, the patient had no hemoptysis and her $\mathrm{SpO}_{2}$ was $98 \%$ on room air. Spirometry on day 14 revealed moderate restrictive defect (Table 1) and she was discharged from hospital. At follow-up clinic, the patient was symptomfree. She was continued on oral steroids for 4 weeks and

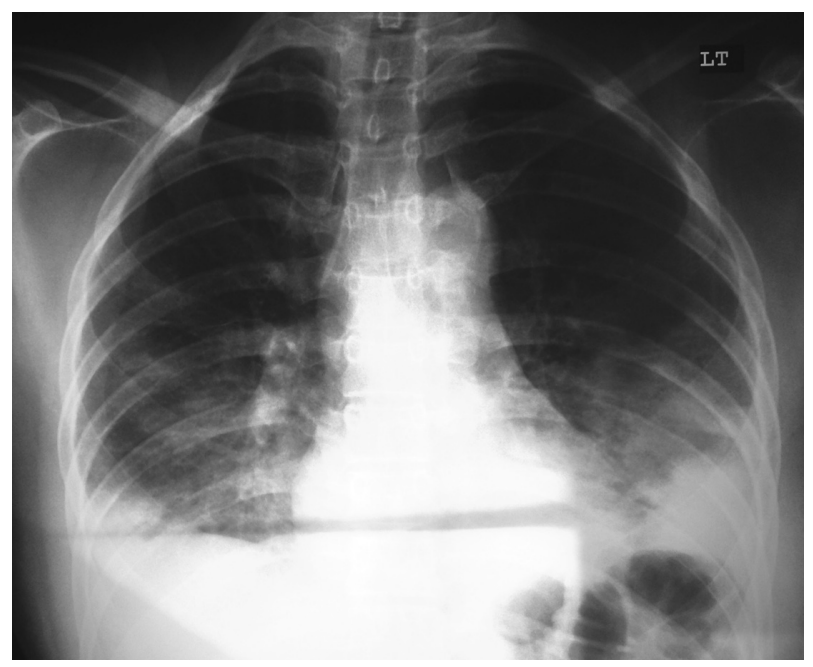

Figure 2 Chest $X$-ray showing bilateral patchy opacification.

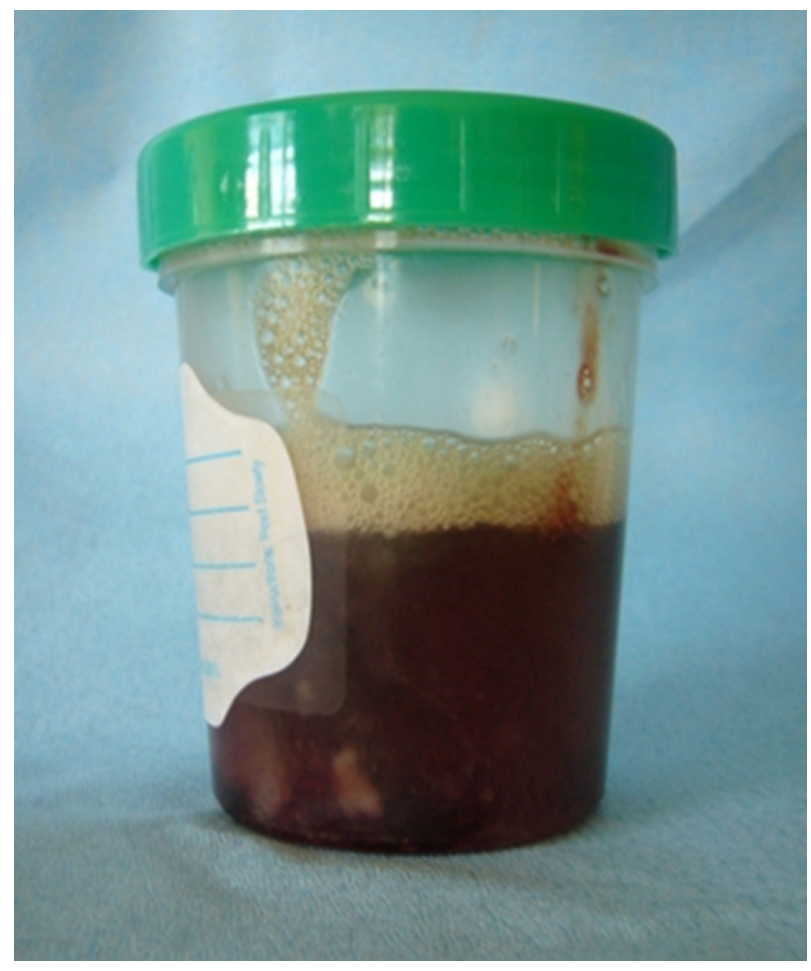

Figure 3 Hemoptysis contents with whitish material admixed on the sputum.

anticoagulated with warfarin for 6 months. Radiological resolution and spirometry normalization (Table 1) occurred after 4 weeks, whereas, elevated AST were normalized only after 8 weeks.

\section{Discussion}

Liquid silicone is a polymer (dimethylpolysiloxane) that has been widely used for aesthetic purposes since the 1960s. ${ }^{1}$ Despite the dangers and long history of fatalities, disease, and disfigurement caused by silicone injection, its illicit use is still common around the world.

Two distinct patterns of clinical presentation are seen after injection of silicone enters the systemic circulation: either respiratory distress, which occurred in this present report, or severe neurological changes. ${ }^{2}$ The first case of

Table I Spirometry on day 14 (after hemoptysis control) and at follow-up clinic (after I month)

\begin{tabular}{lll}
\hline & Day I4 & I month \\
\hline $\mathrm{FEV}_{1} / \mathrm{FVC} \%$ & 90.8 & 86.5 \\
$\mathrm{FEV}_{1}$ & $1.38 \mathrm{~L}(6 \mathrm{I} \%$ of predicted $)$ & $1.86 \mathrm{~L}(82 \%$ of predicted $)$ \\
$\mathrm{FVC}$ & $1.52 \mathrm{~L}(58 \%$ of predicted $)$ & $2.15(82 \%$ of predicted $)$ \\
$\mathrm{FEF}_{25 \%-75 \%}$ & $2.29(62 \%$ of predicted $)$ & $2.74(75 \%$ of predicted $)$ \\
\hline
\end{tabular}

Abbreviations: $\mathrm{FEV}_{\text {, }}$ forced expiratory volume in the first second of expiration; FVC, forced vital capacity; FEF, forced expiratory flow, midexpiratory phase. 
pneumonitis following silicone injection was described in $1975 .{ }^{1}$ The acute form of pneumonitis following silicone injection, as seen in this patient, appears immediately or within 24 hours after injection, with sudden-onset dyspnea, tachycardia, tachypnea, fever, and, occasionally, chest pain or hemoptysis. The pathogenesis of acute pneumonitis involves a process of pulmonary embolism following the diffusion of the silicone into the circulatory system, encouraged by high local tissue pressure, massages, migration, or direct injection. ${ }^{3}$

The index case presented with severe respiratory distress a few hours after silicone injection. With incomplete history from the patient, PE with acute interstitial lung inflammation was suspected. Now, a negative multidetector CT (CTPA) is an adequate criterion for excluding $\mathrm{PE}$ in patients with a nonhigh clinical probability of PE. ${ }^{4}$ However, this case belonged to a high probability class and subsegmental emboli were feasible. Whether patients with a negative CT and a high clinical probability should be further investigated by other methods is controversial. Moreover currently there are no straightforward accepted guidelines for treatment of subsegmental PE.

Additionally silicone embolization to the lung is associated with alveolar hemorrhage. ${ }^{5}$ In the present case, hemoptysis might be secondary to alveolar hemorrhage and/or pulmonary infarction, which was managed with two units of packed red blood cells transfusion. Normal connective tissue and coagulation profiles, renal functions, and anatomically normal vasculature in CT scan precluded the possibility of other causes for pulmonary hemorrhage. Despite its high value, bronchoscopy was deferred due to potential worsening hypoxemia. It is a well-known fact that arterial oxygen tension routinely decreases by 10 to $20 \mathrm{mmHg}$ after uncomplicated fiberoptic bronchoscopy, and hypoxemic patients are at high risk for developing respiratory failure or serious cardiac arrhythmias. $^{6,7}$
Systemic complications have also been reported after silicone use and include mastitis, granulomatous hepatitis, connective tissue disease, lymphadenopathy, and acute febrile reaction. ${ }^{1}$ This patient's persistently elevated AST may have occurred on account of silicone migration to the liver, but conservative treatment was undertaken and resolution was complete.

This case highlights a serious complication of an apparently innocuous process, of which clinicians and the public should be made aware. Clandestine injection of silicone for body enhancement is common and clinicians should be aware of potential complications. ${ }^{8}$ A history of cosmetic procedures involving silicone should be considered in unusual cases of the nature presented here.

\section{Disclosure}

The authors declare no conflicts of interest in this work.

\section{References}

1. Ellenbogen R, Ellenbogen R, Rubin L. Injectable fluid silicone therapy: human morbidity and mortality. JAMA. 1975;234:308-309.

2. Schmid A, Tzur A, Leshko L, Krieger BP. Silicone embolism syndrome: a case report, review of the literature, and comparison with fat embolism syndrome. Chest. 2005;127:2276-2281.

3. Pastor E, Andreu AL, Chiner E. Acute pneumonitis and adult respiratory distress syndrome after subcutaneous injection of liquid silicone. Arch Bronconeumol. 2005;41:702-703.

4. Guidelines on the diagnosis and management of acute pulmonary embolism, The Task Force for the Diagnosis and Management of Acute Pulmonary Embolism of the European Society of Cardiology (ESC). Eur Heart J. 2008;29:2276-2315.

5. Parikh R, Karim K, Parikh N, Han P, Daoko J, Shamoon FE. Case report and literature review: acute pneumonitis and alveolar hemorrhage after subcutaneous injection of liquid silicone. Ann Clin Lab Sci. 2008;38: 380-385.

6. Levine SJ, Stover D. Bronchoscopy and related techniques. In: Levine SJ, editor. Respiratory Disease in the Immunosuppressed Host. Philadelphia, PA: JB Lippincott; 1991:73-93.

7. Goldstein RA, Rohatgi PK, Bergofsky EH, et al. Clinical role of bronchoalveolar lavage in adults with pulmonary disease. Am Rev Respir Dis. 1990;142:481-486.

8. Clark RF, Cantrell FL, Pacal A, Chen W, Betten DP. Subcutaneous silicone injection leading to multi-system organ failure. Clin Toxicol (Phila). 2008;46:834-837.

\section{Publish your work in this journal}

The International Journal of General Medicine is an international, peer-reviewed open-access journal that focuses on general and internal medicine, pathogenesis, epidemiology, diagnosis, monitoring and treatment protocols. The journal is characterized by the rapid reporting of reviews, original research and clinical studies across all disease areas.

\section{Dovepress}

A key focus is the elucidation of disease processes and management protocols resulting in improved outcomes for the patient.The manuscript management system is completely online and includes a very quick and fair peer-review system. Visit http://www.dovepress.com/ testimonials.php to read real quotes from published authors. 